\title{
Different thresholds of tissue-specific dose-responses to growth hormone in short prepubertal children
}

\author{
Ralph Decker ${ }^{1 *}$, Anders Nygren ${ }^{1}$, Berit Kriström², Andreas FM Nierop ${ }^{3}$, Jan Gustafsson ${ }^{4}$,
} Kerstin Albertsson-Wikland ${ }^{1}$ and Jovanna Dahlgren ${ }^{1}$

\begin{abstract}
Background: In addition to stimulating linear growth in children, growth hormone (GH) influences metabolism and body composition. These effects should be considered when individualizing GH treatment as dose-dependent changes in metabolic markers have been reported. Hypothesis: There are different dose-dependent thresholds for metabolic effects in response to $\mathrm{GH}$ treatment.

Method: A randomized, prospective, multicentre trial TRN 98-0198-003 was performed for a 2-year catch-up growth period, with two treatment regimens (a) individualized $\mathrm{GH}$ dose including six different dose groups ranging from $17-100 \mu \mathrm{g} / \mathrm{kg} /$ day $(\mathrm{n}=87)$ and (b) fixed $\mathrm{GH}$ dose of $43 \mu \mathrm{g} / \mathrm{kg} /$ day $(\mathrm{n}=41)$. The individualized $\mathrm{GH}$ dose group was used for finding dose-response effects, where the effective GH dose (ED 50\%) required to achieve $50 \% \Delta$ effect was calculated with piecewise linear regressions.

Results: Different thresholds for the GH dose were found for the metabolic effects. The GH dose to achieve half of a given effect (ED 50\%, with 90\% confidence interval) was calculated as $33( \pm 24.4) \mu \mathrm{g} / \mathrm{kg} /$ day for $\Delta$ left ventricular diastolic diameter (cm), 39( \pm 24.5$) \mu \mathrm{g} / \mathrm{kg} /$ day for $\Delta$ alkaline phosphatase $(\mu \mathrm{kat} / \mathrm{L}), 47( \pm 43.5) \mu \mathrm{g} / \mathrm{kg} /$ day for $\Delta$ lean soft tissue (SDS), $48( \pm 35.7) \mu \mathrm{g} / \mathrm{kg} /$ day for $\Delta$ insulin (mU/L), 51 $( \pm 47.6) \mu \mathrm{g} / \mathrm{kg} /$ day for $\Delta$ height (SDS), and $57( \pm 52.7) \mu \mathrm{g} / \mathrm{kg} /$ day for $\Delta$ insulin-like growth factor I (IGF-I) SDS. Even though lipolysis was seen in all subjects, there was no dose-response effect for $\Delta$ fat mass (SDS) or $\Delta$ leptin $\mathrm{ng} / \mathrm{ml}$ in the dose range studied. None of the metabolic effects presented here were related to the dose selection procedure in the trial.

Conclusions: Dose-dependent thresholds were observed for different GH effects, with cardiac tissue being the most responsive and level of IGF-I the least responsive. The level of insulin was more responsive than that of IGF-I, with the threshold effect for height in the interval between.
\end{abstract}

Keywords: GH deficiency, GH sensitivity, GH responsiveness, Idiopathic short stature, GH dose-effect, Metabolic effects, Lipolysis

\section{Background}

In addition to stimulating linear growth in children, growth hormone $(\mathrm{GH})$ influences metabolism and body composition. For several decades it has been known, based on results of in vitro and in vivo studies, that $\mathrm{GH}$ has effects on amino acid transport, protein synthesis

\footnotetext{
* Correspondence: Ralph.Decker@vgregion.se

'Göteborg Pediatric Growth Research Centre (GP-GRC), Department of Pediatrics, Institute of Clinical Sciences, The Sahlgrenska Academy at University of Gothenburg, Gothenburg, Sweden

Full list of author information is available at the end of the article
}

[1-3], lipolysis [4,5] and glucose metabolism [2,6,7] after targeting receptors at different tissues [8]. In addition, several studies have evaluated metabolic responses to GH treatment [9-16]. GH replacement therapy in children induces favourable changes in metabolic indices and improves body composition, bone density and remodelling, physical and cardiac performance, as well as overall quality of life [12-17]. If individual responsiveness is taken into account, the metabolic response to GH treatment does not differ markedly between short children with and without classic GH deficiency (GHD)

\section{Biomed Central}


[18]. The data at baseline has previously been published [19]. It has been discussed whether any cut-off level of $\mathrm{GH}$ secretion chosen to distinguish between children with GHD and idiopathic short stature (ISS) may be arbitrary $[19,20]$.

Dose-dependency with regard to $\mathrm{GH}$ has only been studied in a few clinical trials. It has been shown that $\mathrm{GH}$ treatment increases adult height in a dose-dependent manner in children with ISS [21]. GH dose-dependency of metabolic variables has not been clearly defined in short children owing to a lack of controlled trials on metabolic outcomes in response to different GH doses.

In a randomized, controlled, clinical trial we have recently shown that the anabolic and lipolytic effects of GH can be dissociated in a GH dose range between 17 and $100 \mu \mathrm{g} / \mathrm{kg} /$ day. Anabolism was found to be dosedependent while lipolysis was not [18], despite a lipolytic effect being noted in all subjects. It was interpreted that the lipolytic effect of $\mathrm{GH}$ was overridden in the dose range used, and that dose-dependency may therefore become apparent at lower doses.

The objective of the present study was to investigate and compare the $\mathrm{GH}$ doses required to achieve different metabolic responses. The hypothesis was that there are dose-dependent thresholds for different tissues and metabolic functions. It was expected that the results would provide insight into the effective $\mathrm{GH}$ dose required to influence metabolic processes and cardiac tissue in short children with different GH secretion capacities and GH responsiveness. The key question was "What is the appropriate GH dose in prepubertal children to compensate for deteriorations in body composition and to avoid unfavourable metabolic effects?'

\section{Subjects and methods \\ Ethical consideration}

The study protocol (TRN 98-0198-003) was approved by the Ethics Committees of the Universities of Göteborg (for Göteborg and Halmstad), Umeå, Uppsala and Malmö and the Medical Product Agency of Sweden. Written informed consent was obtained from all parents and from children if possible. The study was performed in accordance with the Declaration of Helsinki and Good Clinical Practice.

\section{Subjects and study protocol}

The study was a 2-year prospective, randomized, openlabel, multicentre trial in short prepubertal children with isolated GHD or ISS [22] naïve to GH treatment. Individual GH responsiveness was estimated by our growth response prediction model for children with GHD and ISS [23], and the patients were randomized in 1:2 proportions to receive either a standard or an individualized $\mathrm{GH}$ dose during 2 years of catch-up growth to a preset growth target, mid-parental height SDS $\left(\mathrm{MPH}_{\mathrm{SDS}}\right)$. Randomization variables included gender, weight ${ }_{\mathrm{SDS}}$ at birth, height ${ }_{\text {SDS }}$ at age 1 year, $\mathrm{GH}_{\max } \mathrm{AITT}$ (during an arginine-insulin tolerance test), $\mathrm{GH}_{\max } 24 \mathrm{~h}$ profile (during $24 \mathrm{~h}$ spontaneous $\mathrm{GH}$ sampling), age and height ${ }_{\mathrm{SDS}}$ at start, the child's height ${ }_{\mathrm{SDS}}$ difference to its $\mathrm{MPH}_{\mathrm{SDS}}$ (diff $\left.\mathrm{MPH}_{\mathrm{SDS}}\right)$ at start, and predicted $1^{\text {st }}$ year $\Delta$ height ${ }_{\mathrm{SDS}}$ [23]. No patients with syndromes, chronic diseases or complete GH insensitivity were included in the study population.

Upon inclusion, all patients had a height $t_{\text {SDS }}$ below -2.0 [24] and a growth velocity below -1.0 SDS. 128 children (38 girls, 90 boys) followed the protocol [22]. Both the results from the $\mathrm{GH}_{\max }$ AITT and the $\mathrm{GH}_{\max } 24 \mathrm{~h}$ profile were used to separate children with GHD from those with ISS. Classic GHD was defined based on a $\mathrm{GH}_{\max }$ below $32 \mathrm{mU} / \mathrm{L}$ (using polyclonal assay, WHO IRP 80-505) corresponding to $24 \mathrm{mU} / \mathrm{L}$ (using monoclonal assay) and equivalent to the 'old cutoff of $10 \mu \mathrm{g} / \mathrm{L}$ ' [18]. According to this definition, 39 children had isolated GHD and 89 had ISS. However, when using $\mathrm{GH}_{\max }$ results exclusively from the AITT, 90 children were assigned the diagnosis of GHD and 38 the diagnosis of ISS. Additionally, all of our patients fulfilled the criteria for GHD according to a growth velocity lesser than -1.0 SDS, IGF-I below -1 SD of sex and age specific references, bone age retardation of more than 1,5 years $[18,22]$.

To address the question concerning GH thresholds and to study the possible dose-dependency, the analysis focused on the individualized treatment group $(n=87)$. We used data from prepubertal children included in a trial, randomized to individual GH doses in the range of $17-100 \mu \mathrm{g} / \mathrm{kg} / \mathrm{d}$ according to their growth-related $\mathrm{GH}$ responsiveness; with dose-adjustment for the estimated difference to the preset height target (i.e. $\mathrm{MPH}_{\mathrm{SDS}}$ ) at 2 years on GH in order to make it possible for each child to reach its $\mathrm{MPH}_{\mathrm{SDS}}$ within a 2 year period. [22]. Children with a higher predicted growth response, calculated before start of treatment, received a lower individual $\mathrm{GH}$ dose, and those with a lower predicted growth response received a higher $\mathrm{GH}$ dose. The $\mathrm{GH}$ doses used in the individualized-dose group were $17 \mu \mathrm{g} / \mathrm{kg} /$ day $(\mathrm{n}=3), 33$ $\mu \mathrm{g} / \mathrm{kg} /$ day $(\mathrm{n}=27), 40 \mu \mathrm{g} / \mathrm{kg} /$ day $(\mathrm{n}=10), 50 \mu \mathrm{g} / \mathrm{kg} /$ day $(\mathrm{n}=26), 66 \mu \mathrm{g} / \mathrm{kg} /$ day $(\mathrm{n}=14)$, and $100 \mu \mathrm{g} / \mathrm{kg} /$ day $(\mathrm{n}=7)$ : the mean $\mathrm{GH}$ dose in this group was $49 \mu \mathrm{g} / \mathrm{kg} /$ day [22].

The fixed GH dose group was used as a control group for estimating a metabolic effect of the dose selection procedure in the trial by regressing the metabolic variables on the intended dose of the fixed GH dose group. The intended dose is the $\mathrm{GH}$ dose that the patients would have been given if they had been randomized to the group treated with individualized dose. Since this group was randomised to receive the fixed $\mathrm{GH}$ dose, any 
metabolic effect of the intended dose implicates an effect of the dose selection procedure independent of the dose given. None of the six metabolic effects appeared to be related to the dose selection procedure in the trial. $\Delta$ ALP, $\Delta \mathrm{LST}_{\mathrm{SDS}}, \Delta$ insulin and $\Delta \mathrm{IGF}_{\mathrm{I}} \mathrm{IDS}_{\text {showed no sig- }}$ nificant effect, whereas $\Delta$ LVDd and to a lesser extend $\Delta$ height $_{\text {SDS }}$ were even somewhat negative correlated to the intended dose of the fixed GH dose group (data not shown).

\section{Laboratory analyses and growth evaluation}

$\mathrm{GH}$ and insulin-like growth factor I (IGF-I) assays were performed at the Göteborg Pediatric Growth Research Center (GP-GRC) laboratory (accredited number 1899). For analyses of serum IGF-I, leptin, insulin, alkaline phosphatase (ALP) and plasma GH, see our previous publication [18]. IGF-I was converted to SDS [25].

\section{Growth evaluation}

Height was measured [22] and converted to SDS [24], as previously described, with use of the childhood component of the total reference [26].

\section{Body composition}

Body composition was measured by dual-energy X-ray absorptiometry (DXA), using only one DPX-L scanner (Lunar Co., Madison, WI) at each study centre. Regular harmonization between the centres was performed following GCP/GMP. DXA assessment results in a threecompartment model of the body consisting of fat mass, lean soft tissue (LST) mass and bone mineral content (BMC). All analyses were conducted using the extended analysis program for total body analysis including bone mineral density (BMD).

\section{Echocardiography}

Echocardiography was performed by four pediatric cardiologists and one experienced sonographer. Each child was examined longitudinally throughout the study by the same cardiologist/ sonographer. Interventricular septum thickness (IVSd), left ventricular diameter (LVDd) and left ventricular posterior wall (LVPWd) thickness were measured in diastole using M-mode. Left ventricular mass (LVM) was calculated using Devereux's anatomically corrected formula [27].

\section{Statistics}

For all analyses, the assumptions of normality were assessed by analysis of skewness, kurtosis and frequency histograms. A p-value of $<0.05$ was considered to be statistically significant.

Delta values ( $\Delta$-values) for the metabolic variables were calculated in order to quantify changes at 2 year of treatment compared with baseline. S-shaped piecewise linear regression models were fitted with $\mathrm{GH}$ dose as the predictor variable and the $\Delta$-value of the metabolic variables as response variables. It consists of 3 pieces: a horizontal head and tail and a linear piece in the middle and was plotted based on the GH-dose effect on the dependent metabolic variables. Fitting this regression comes down to fitting a bounded linear model with four parameters; the usual slope and intercept of a linear regression and an upper and lower bound for the fitted model values. The GH dose effect was given by the maximum range of the fitted piecewise function, which is equal to the difference between the fitted upper and lower bound. Half of the GH dose effect on the respective variables was calculated based on the value halfway between the lowest and highest level of the piecewise function ( $50 \% \Delta$ effect). The number of cases within each dose group was taken into account by weighting. Corresponding $90 \%$ confidence bands were calculated.

The fitted upper and lower bounds minus the fitted intercept, divided by the fitted slope provide the two breakpoints of the predictor variable separating the middle linear part from the horizontal head and tail. The ED $50 \%$ required to achieve (50\% $\Delta$ effect) is located halfway the two breakpoints of the predictor variable and a corresponding $90 \%$ confidence interval is computed. We considered the ED 50\% values of pairs of metabolic variables as significantly different if their ED50\% values were mutually outside each other's $90 \%$ confidence interval, each providing a $5 \%$ significance level one-sided. This ED $50 \%$ is halfway the two breakpoints of the predictor variable separating the middle linear part from the horizontal head and tail.

A one-way analysis of variance (ANOVA) with $\mathrm{GH}$ dose as a bounded continuous predictor was performed to test the piecewise linear $\mathrm{GH}$ effect. A non-parametric comparison of group means (robust test of equality of means - Welch test and Brown-Forsythe test) was conducted when variances of dependent variables were not equal across groups. To examine the influence from the $17 \mu \mathrm{g} / \mathrm{kg} /$ day dose group consisting of only three children, analysis were repeated with these children excluded. No significant differences resulted compared to the the complete study population. Only data consistently significant were reported.

Statistical analyses were performed with SPSS 17.0 (SPSS Inc., Chicago, USA) and with Matlab version 7.13.0 (R2011b, The Mathworks, Natick, MA, USA).

\section{Results}

\section{Dose-dependency}

The variables were analyzed as $\Delta$ values between the start and 2 years of $\mathrm{GH}$ treatment. For each of the six dose groups, the mean $\Delta$ was calculated ( $\Delta$ dose-group mean), and is shown for the 87 children receiving 
individualized GH treatment, Additional file 1. The dose-response relationships are shown in Figure 1. When performing ANOVA and linear regression, substantial lipolytic effects were seen in all groups as demonstrated by changes in the variables fat mass and leptin from baseline to 2 yrs of treatment; however, no dose-response differences were observed between the GH dose groups for $\Delta$ fat mass SDS,$\Delta$ leptin, $\Delta$ bone age, $\Delta$ BMD, $\Delta$ IVSd or $\Delta$ LVPWd (data not shown). The $\Delta$
LVM was found to be significant at the initial analysis (ANOVA p-value $=0.013$ ) and ED $50 \%$ of $36 \mu \mathrm{g} / \mathrm{kg} /$ day. Excluding the small $17 \mu \mathrm{g} / \mathrm{kg} /$ day group, significance was lost and the data is not included in Additional file 1.

\section{Effective $\mathrm{GH}$ dose at ED 50\%}

Dose-dependent increases of the dose-group means of $\Delta$ LVDd, $\Delta$ ALP, $\Delta$ LST $_{\mathrm{SDS}}, \Delta$ insulin, $\Delta$ height $_{\mathrm{SDS}}$ and $\Delta$ IGF-I $_{\mathrm{SDS}}$ at 2 years of individualized $\mathrm{GH}$ treatment a $\%$ of dLVDd,dALP,dLST, piecewise linear regression
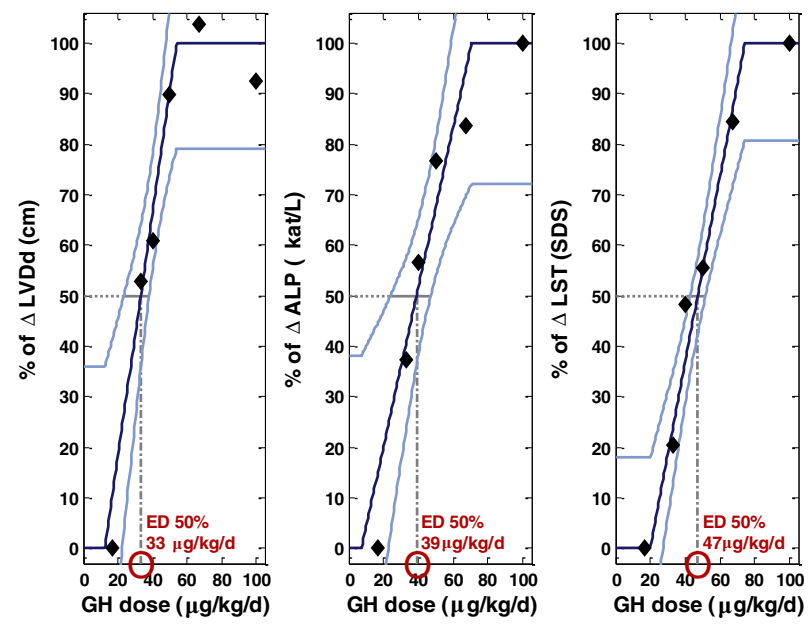

$\%$ of dInsulin,dHeight,dIGF-I, piecewise linear regression
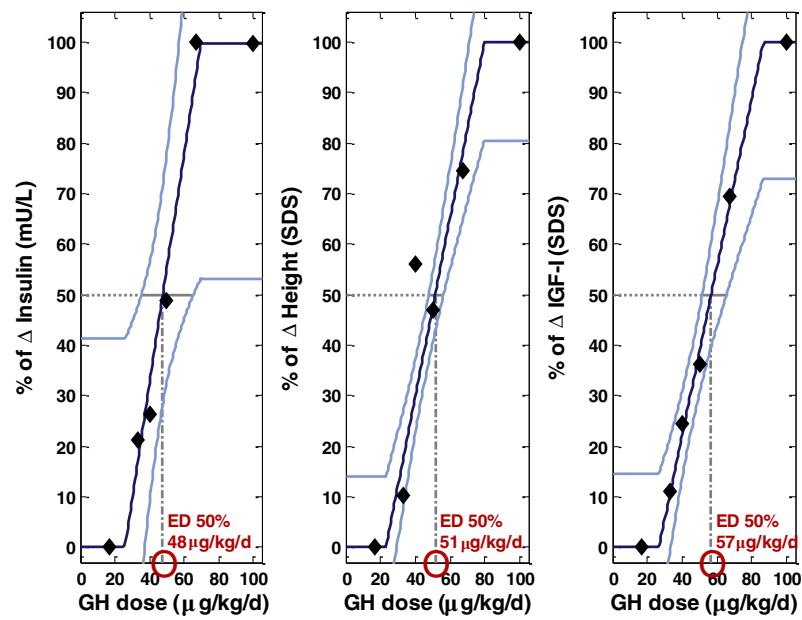

b

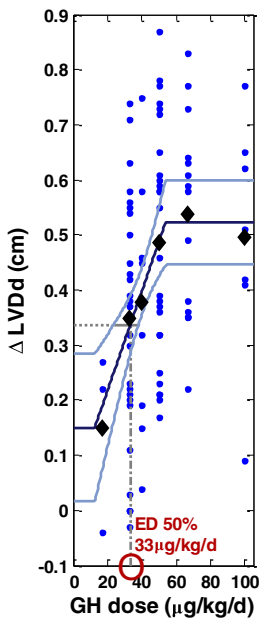

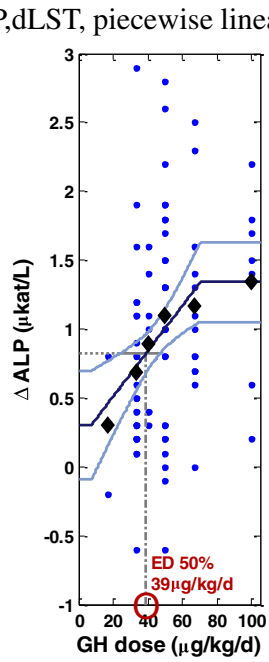

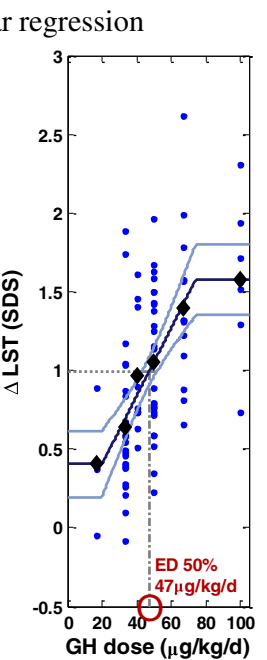

Figure 1 a.Dose-response relationship of outcome variables - relative changes. Dose-response relationships between metabolic outcome variables fitted with S-shaped piecewise linear regression lines with corresponding $90 \%$ confidence intervals. The $y$-axis is scaled as percent (\%) of the maximum range of the fitted piecewise function. The lowest level of the piecewise function is set to $0 \%$ and the highest to $100 \%$. The diamonds indicate the percentage change $(\Delta)$ in dose-group means (between start and 2 years) of the metabolic variables on the $y$-axis vs GH dose on the X-axis. LVDd: Left ventricular diameter in diastole, ALP: alkaline phosphatase, LST: lean soft tissue, IGF-l: insulin-like growth factor I. The effective GH dose (ED 50\%) required to achieve half of the dose effect is calculated according to the linear regression equation of the middle part of the piecewise linear GH dose effect. b.Dose-response relationship of outcome variables - absolute changes. Dose-response relationship of metabolic outcome variables fitted with S-shaped piecewise linear regression lines with corresponding $90 \%$ confidence intervals. The small dots indicate the change $(\Delta)$ in response values (between start and 2 years) for 87 children receiving individualized growth hormone (GH) treatment on the $y$-axis vs GH dose on the x-axis. The diamonds show the dose-group means. LVDd: Left ventricular diameter in diastole, ALP: alkaline phosphatase, LST: lean soft tissue, IGF-I: insulin-like growth factor I. The effective GH dose (ED 50\%) required to achieve half of the dose effect is calculated according to the linear regression equation of the middle part of the piecewise linear GH dose effect. 
are plotted in Figure 1. All values in Figure 1a are given as percentages of the maximum range, while Figure $1 \mathrm{~b}$ shows the same data, but now with the original scale. The lower the ED 50\%, the higher is the responsiveness of a given variable. The ED $50 \%$ was lowest for $\Delta$ LVDd and highest for $\Delta$ IGF-I $_{\text {SDS }}$ (). The ED $50 \%$ for $\Delta$ ALP, $\Delta$ LST, $\Delta$ insulin, and $\Delta$ height $_{\text {SDS }}$ lay in the interval between these two extremes in ascending order. Differences between the $\Delta$ dose-group means for the metabolic variables were tested for a piecewise linear GH dose effect by one-way ANOVA with GH dose as a bounded continuous predictor, Additional file 1.

\section{Dose-responses to $\mathrm{GH}$ treatment}

Classic dose-response curves are depicted for the six different GH doses in the 87 children receiving individualized GH treatment, Figure 2.

Absolute dose-group means of $\mathrm{LST}_{\mathrm{SDS}}$, insulin $(\mathrm{mU} / \mathrm{L})$, and IGF-ISDS at start of treatment were set to $0 \%$ and compared with values from 1 and 2 years of treatment. IGF-ISDS at start of treatment was also compared with values at 3 months of treatment.

Low GH doses were associated with the smallest responses. High GH doses resulted in marked responses, with an increase in $\mathrm{LST}_{\mathrm{SDS}}$ by more than $60 \%$ relative to baseline and an increase of more than $250 \%$ for levels of insulin and IGF-I $\mathrm{SDS}$ during the 2-year treatment period, Figure 2.

\section{Thresholds of GH dose effects}

An overview of the principal relationships between $\mathrm{GH}$ dose effects is shown in Figure 3. GH dose thresholds, correspond to the ED 50\%, are depicted as a staircase with increasing $\mathrm{GH}$ doses needed to achieve a certain metabolic effect. Variables are given as $\Delta$ between start and at 2 years of $\mathrm{GH}$ treatment.

\section{Discussion}

In the present study, different thresholds for tissue and metabolic responses to $\mathrm{GH}$ treatment were found in short children who had varying GH secretion capacities, as well as varying responsiveness to $\mathrm{GH}$.

\section{Cardiac response to $\mathrm{GH}$}

Cardiac tissue, estimated by LVDd, was found to be the most GH-sensitive of the variables evaluated (effects seen from a dose of $33 \mu \mathrm{g} / \mathrm{kg} / \mathrm{d}$ ). This is in line with the findings of Capalbo et al. [28] who found that LVDd increased during treatment with a dose of $30 \mu \mathrm{g} / \mathrm{kg} / \mathrm{d}$. From the available data, it is difficult to draw conclusions concerning the mechanism responsible for $\mathrm{GH}$ effects on heart size. We have, however, previously shown the presence of GH receptors in cardiac tissue in children, indicating that a direct effect of $\mathrm{GH}$ on the heart is likely [29]. Even though GH responsiveness was high, there were no adverse effects seen on any measurement of cardiac function or on blood pressure during the study [30].

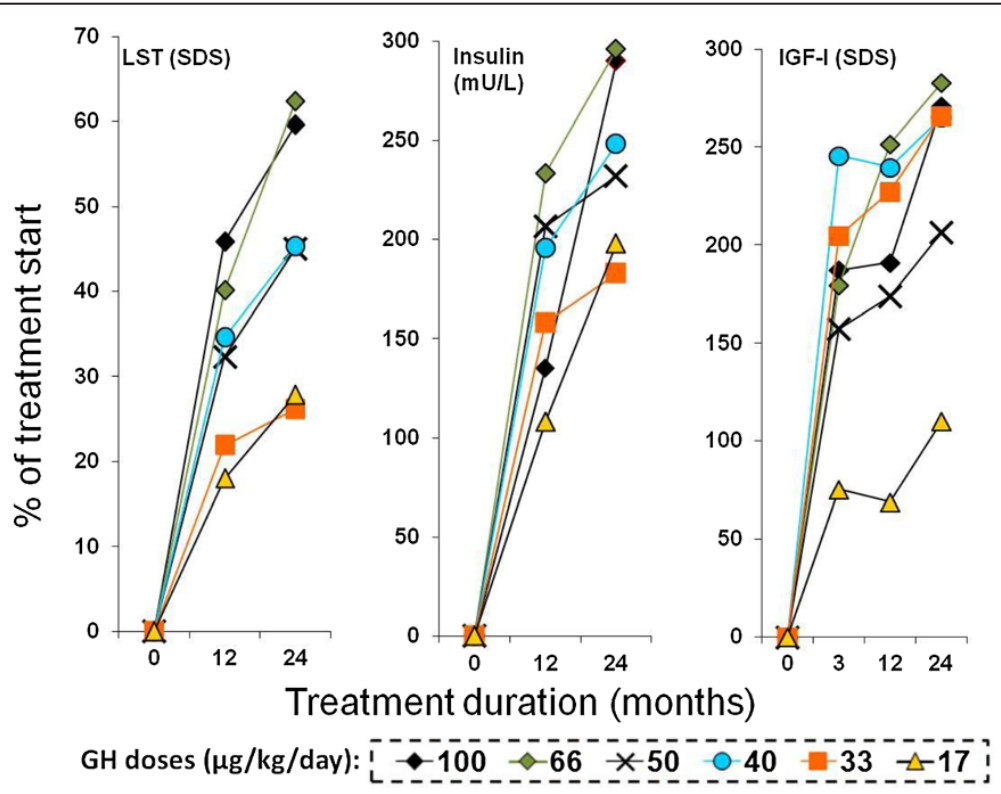

Figure 2 Examples of Dose-response relationship. Dose-response relationship for the six different growth hormone (GH) doses in 87 children receiving individualized GH treatment. The dose-group means at start of treatment are set to $0 \%$ increase from baseline values, and compared with dose group mean values at 3 months, and after 1 and 2 years of treatment. LST: Lean soft tissue, IGF-I: Insulin-like growth factor I, SDS: standard deviation score. (The absolute $\Delta$ values are presented in ref 18). 


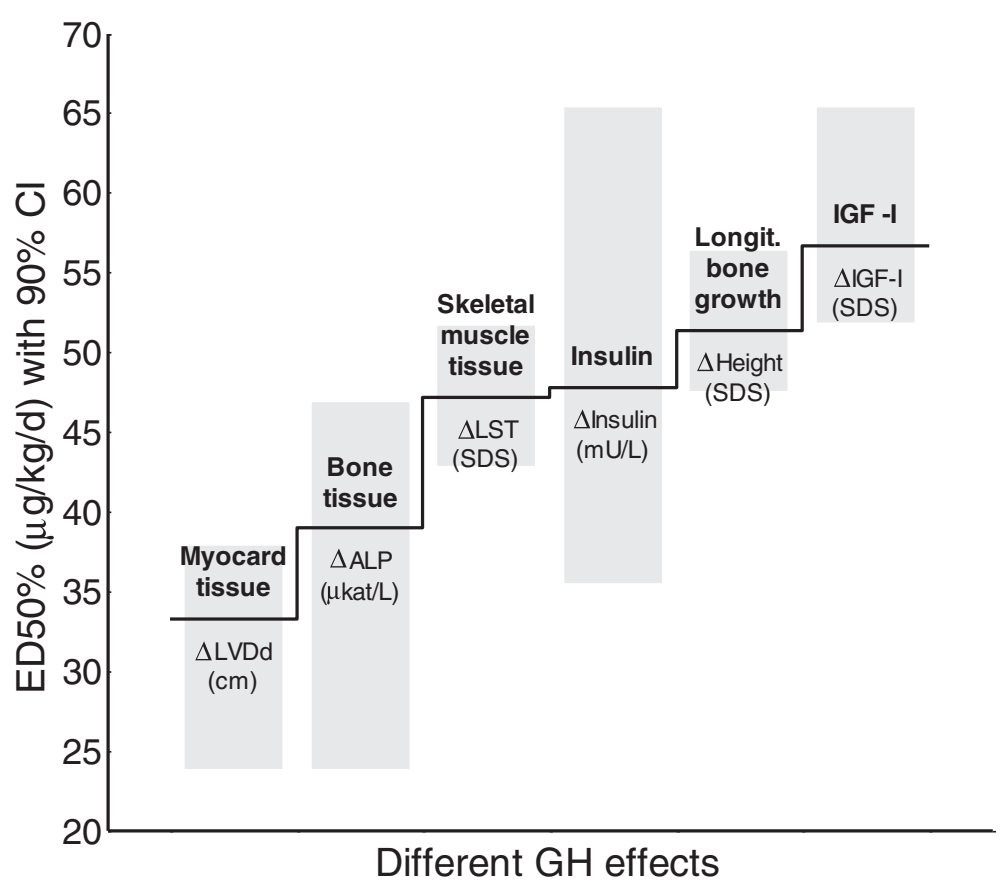

Figure 3 The threshold staircase hypothesis. The "threshold hypothesis" is presented in accordance with results from the present study as a staircase of growth hormone (GH) dose needed for an effect (no scaling). Dose-response thresholds for metabolic markers represent different metabolically active tissues or metabolic functions compared with the longitudinal growth response. LVDd: Left ventricular diameter in diastole, ALP: alkaline phosphatase, LST: lean soft tissue, IGF-I: insulin-like growth factor I. Variables are given as change ( $\Delta$ ) between start and at 2 years of GH treatment. The light-grey boxes mark the $90 \%$ confidence interval (CI).

\section{GH dose-effect on body composition}

It has been shown that GH treatment at a dose of $57 \mu \mathrm{g} / \mathrm{kg} / \mathrm{d}$ given to children born small for gestational age (SGA) can lead to an increase in muscle mass, and a concomitant decrease in fat mass [31]. However, data showing a dose-dependency increase in LST are lacking. We found that LST mass increased in a dosedependent manner for the six GH doses administered. This effect was most marked at GH doses above 33 $\mu \mathrm{g} / \mathrm{kg} / \mathrm{d}$, and the ED $50 \%$ for gain in LST mass was in the mid-range $(47 \mu \mathrm{g} / \mathrm{kg} / \mathrm{d})$. This dose is in the same range as that found to promote longitudinal bone growth $(51 \mu \mathrm{g} / \mathrm{kg} / \mathrm{d})$, confirming our previous findings of anabolic $\mathrm{GH}$ effects.

As demonstrated previously using principal component analysis [18], a strong lipolytic effect was found for all GH doses, seen by changes in fat mass and fat mass index, but no GH dose-response effect was seen. A possible explanation is that in the dose range studied the lipolytic effect had already reached its maximum, making lipolytic variables the most sensitive to GH. Early leptin reduction after the start of $\mathrm{GH}$ treatment was found previously to be positively correlated with first year growth response in a group of short children treated with $33 \mu \mathrm{g} / \mathrm{kg} /$ day; however, there was a wide range in $\Delta$ leptin levels as for growth response; at that time no individual responsiveness was possible to estimate [11]. It is well known that fat mass decreases in GH-deficient adults when they are treated with GH [32]. Further studies are needed to determine the dose response for the lipolytic effects at lower doses in children.

\section{GH effect on alkaline phosphatase}

Increased serum bone-specific ALP is known to be a reliable and early sign of increased bone metabolism and correlates to first year growth response in GHdeficient children [33]. In the present study, ALP activity was found to be more responsive than longitudinal bone growth to a given $\mathrm{GH}$ dose.

\section{GH dose-effect on insulin and insulin-sensitivity}

$\mathrm{GH}$ doses above the common dose range of $25-35 \mu \mathrm{g} / \mathrm{kg} /$ $\mathrm{d}$ used for GH-deficient children [34], resulted in greater insulin increases than lower doses, although insulin levels did not exceed the normal range. This confirms previous studies that insulin levels are lower than normal at baseline in GH-deficient individuals [35]. In short children born SGA, no impaired GH dose-response effect on insulin has been reported in a dose range between 33 and $66 \mu \mathrm{g} / \mathrm{kg} / \mathrm{d}$ [36].

$\mathrm{GH}$ exerts both insulin-like and insulin-antagonistic effects in vitro [4]. An insulin-like effect has been 
reported in some in vivo studies [37], but not in all [38]. In the present study the ED 50\% for the insulin enhancement was $48 \mu \mathrm{g} / \mathrm{kg} / \mathrm{d}$, which is very close to the ED 50\% of $51 \mu \mathrm{g} / \mathrm{kg} / \mathrm{d}$ for height gain found in the present study. Thus, the insulin antagonist effect of $\mathrm{GH}$ seems to be equally or more responsive to $\mathrm{GH}$ than the effect on IGF-I. An explanation for this may be that we used SDS for IGF-I, but not for fasting insulin, where $\mathrm{mU} / \mathrm{L}$ was used. Insulin may be required as a growth factor during the catch-up growth phase, so the observation of a dosedependent increase should be viewed as more than just compensation for $\mathrm{GH}$-induced insulin resistance.

\section{GH dose-effect on IGF}

We demonstrated a marked dose-response effect on IGF$\mathrm{I}_{\mathrm{SDS}}$. Thus, as for LST mass, the prediction of growth response is not valid for IGF-I IDS levels. This is in line with findings in groups where individual responsiveness was not addressed, and GH therapy resulted in increasing IGF-I ${ }_{\text {SDS }}$ in a dose-dependent manner in prepubertal children, with more dramatic changes being observed at higher doses (50 and $100 \mu \mathrm{g} / \mathrm{kg} /$ day vs $25 \mu \mathrm{g} / \mathrm{kg} / \mathrm{d}$ ) [39], and $100 \mu \mathrm{g} / \mathrm{kg} / \mathrm{d}$ compared to $43 \mu \mathrm{g} / \mathrm{kg} / \mathrm{d}$ in pubertal GHdeficient patients [40].

In the present study, the ED 50\% for IGF-I IDS was $57 \mu \mathrm{g} / \mathrm{kg} / \mathrm{d}$, which was the highest dose observed for any metabolic variable. Therefore, liver response to IGF-I secretion was found to have a higher threshold than both height gain and muscle growth in the present study.

\section{GH dose-effect on catch-up growth}

In order to be able to compare metabolism and growth, height gain was studied in the present study and not the height target of the study, i.e. the diff $\mathrm{MPH}_{\mathrm{SDS}}$. The growth effect associated with individualized GH doses was quantified and presented in Figure 1. Thus, a GH dose of $51(47,56) \mu \mathrm{g} / \mathrm{kg} / \mathrm{d}$ was necessary in order to achieve half of the height gain. In previously performed studies in children with ISS, GH had a dose-related effect on longitudinal bone growth in the dose ranges of $33-67 \mu \mathrm{g} / \mathrm{kg} / \mathrm{d}$ [21] and 31-47 $\mu \mathrm{g} / \mathrm{kg} / \mathrm{d}$ [41]. In GHdeficient children, an increase in GH dose from 25 to 50 $\mu \mathrm{g} / \mathrm{kg} / \mathrm{d}$ resulted in a sustained increase in growth velocity, whereas in this study no additional effect was observed with a further increase in dose to $100 \mu \mathrm{g} / \mathrm{kg} / \mathrm{d}$, the highest $\mathrm{GH}$ dose in the trial given only to the most non-responsive children [39]. However, in a randomized GH dose study during puberty in GH-deficient children, a dose dependent effect $(33 \mu \mathrm{g} / \mathrm{kg} / \mathrm{d}$ vs. $67 \mu \mathrm{g} / \mathrm{kg} / \mathrm{d}$ ) was found [42]. This is in line with prior evidence for a dose-dependent effect of higher doses on adult height in children with ISS [43]. To summarize, the adult height achieved in GH-deficient children treated with GH replacement therapy has been found to be dose- dependent [34,42], as has adult height in children with ISS $[21,41,43]$.

\section{Effects on metabolism}

There are, however, only a few studies on the metabolic consequences of GH therapy in children. Ciresi et al. [12] studied metabolic parameters in GH-deficient children, but the question of dose-dependency was not investigated. Mauras et al. [40] compared IGF-I levels in two different GH dose groups in adolescents with GHD. Cohen et al. [39] analyzed the response of IGF-I, IGFBP3 , fasting glucose, fasting insulin, HbA1c and height to three different GH doses $(25,50$, and $100 \mu \mathrm{g} / \mathrm{kg} /$ day $)$ in prepubertal GH-deficient children. However, the question of whether there were different metabolic thresholds was neither addressed nor individual responsiveness.

In a recent report on our study group, we found dosedependent effects on height gain, body composition and metabolism [18]. There are no comparable prospective randomized studies. Nevertheless, our data can be compared with reported qualitative effects in response to different GH doses, which suggest that dose-response effects exist $[21,39]$.

Our study included children classified as both GHD and ISS as our study also includes aspects on tissue responsiveness, ranging from high to low within both diagnostic groups. Without a wide range, it would not have been possible to perform our study on the hypothesis of varying thresholds for different tissues and metabolic markers $[19,20]$.

A fact that influences the interpretation of the results is, that the individual $\mathrm{GH}$ dose in the trial was selected based on GH responsiveness according to estimated/ expected growth response and adapted so that the child would reach $\mathrm{MPH}_{\mathrm{SDS}}$ within 2 years, although limited by the set maximal GH dose of $100 \mu \mathrm{g} / \mathrm{kg} / \mathrm{d}$. None of the metabolic effects presented here was found to be related to the dose selection procedure in the trial.

The strengths of the present study are that we were able to compare many different effects within the same individual, as well as assessing inter-individual variations. When monitoring GH treatment in the clinical setting, it is essential to know which processes will be affected and which marker will be the first to react to treatment based on responsiveness. The aim with estimating individual responsiveness is to set a target for treatment effect - it may be growth response for which we now have prediction models. In the future, prediction models may also be constructed for the metabolic markers studied in this paper.

\section{Conclusions}

GH dose-dependent thresholds for different metabolic effect were found in the current study, Figure 3. Cardiac 
tissue was found to be the most responsive to GH treatment, followed by muscle tissue and height gain. Insulin levels incresed, reflecting $\mathrm{GH}$-induced resistance and insulin was found to be more sensitive to GH than IGF-I, suggesting that insulin is as a growth factor during the catch-up growth phase in prepubertal short children.

\section{Additional file}

Additional file 1: Table S1. Increase in studied variables in the different dose groups.

\begin{abstract}
Abbreviations
ALP: Alkaline phosphatase; ANOVA: Analysis of variance; Apo A-II: Apolipoprotein A-II; BMC: Bone mineral content; BMD: Bone mineral density; $\triangle$ : Delta; ED 50\%: Effective dose 50\%; DBP: Diastolic blood pressure; DXA: Dual-energy X-ray absorptiometry; DPX-L: Proper name of the Lunar pencil beam scanner; GH: Growth hormone; GHD: Growth hormone deficiency; GP-GRC: Göteborg Pediatric Growth Research Center; HbA1c: Glycosylated haemoglobin; HDL: High-density lipoprotein; HOMA: Homeostasis model assessment of insulin resistance calculated as ((fasting serum insulin* fasting plasma glucose)/22.5); IGF-I: Insulin-like growth factor I; ISS: Idiopathic short stature; IVSd: Interventricular septal thickness in diastole; LDL: Low-density lipoprotein; Lp(a): Lipoprotein (a); LST: Lean soft tissue; LVDd: Left ventricular diameter in diastole; LVM: Left ventricular mass; LVPWd: Left ventricular posterior wall in diastole; SBP: Systolic blood pressure; SDS: Standard deviation score.
\end{abstract}

\section{Competing interests}

R Decker and A Nygren declare that they have no competing interests. B Kriström declares that she received lecture and consultation fees. J Gustafsson declares that he owns stocks and has received consultation fee, and an unrestricted research grant from Pfizer. AFM Nierop works for Muvara bv, Multivariate Analysis of Research Data, in the Netherlands. K Albertsson-Wikland declares that she received an unrestricted research grant from Pharmacia/Pfizer until 2005 for previous studies and the present study and has received lecture fees. J Dahlgren declares that she received lecture and consultation fees, and received an unrestricted research grant from Pfizer.

\section{Authors' contributions}

All authors contributed intellectually to analyses and interpretation of the data; to the writing and revising of the manuscript; and have all given approval of the final version to be published. Moreover, RD took the lead of the writing and the preliminary analyses; AN contributed with the cardiac variables and further analyses; BK, as study coordinator and investigator both in Gothenburg and in Umeå; AFMN contributed with the final statistical analyses; JG as the Uppsala investigator; KAW as the initiator of the study and principle investigator and JD as a Gothenburg investigator and planned the statistical analyses.

\section{Acknowledgements}

The authors thank participating children and families, the investigators at the different study centres: A. Stefan Aronson, Nils-Östen Nilsson, Torsten Tuvemo, Maria Halldin, Sten A. Ivarsson and Johan Svensson; the regional study teams and colleagues at the University Pediatric Endocrinology centres, the pediatricians and nurses at the county hospitals responsible for caring for the children close to home, and Carola Pfeiffer-Mosesson and Ingela Peacock for data management and conscientious monitoring, and the GP-GRC laboratory led by Irène Leonardsson. We also thank Nils-Gunnar Pehrson for statistical advice and Sten Rosberg for valuable advice. This investigator initiated and sponsored study TRN 98-0198-003 was funded by an unrestricted research grant by Pharmacia/Pfizer. Financial support was also obtained from Swedish Research Council no 7509, University Hospital (ALF) and West Sweden Region (VGR) grants.

\section{Author details}

'Göteborg Pediatric Growth Research Centre (GP-GRC), Department of Pediatrics, Institute of Clinical Sciences, The Sahlgrenska Academy at University of Gothenburg, Gothenburg, Sweden. ${ }^{2}$ Institute of Clinical Sciences, Department of Pediatrics, Umeå University, Umeå, Sweden. ${ }^{3}$ Muvara bv, Multivariate Analysis of Research Data, Leiderdorp, Netherlands. ${ }^{4}$ Department of Women's and Children's Health, Uppsala University, Uppsala, Sweden.

Received: 13 June 2012 Accepted: 11 October 2012

Published: 1 November 2012

\section{References}

1. Kostyo JL: Rapid effects of growth hormone on amino acid transport and protein synthesis. Ann N Y Acad Sci 1968, 148(2):389-407.

2. Albertsson-Wikland K, Isaksson O: Time course of the effect of growth hormone in vitro on amino acid and monosaccharide transport and on protein synthesis in diaphragm of young normal rats. Endocrinology 1978, 102(5):1445-1451.

3. Hayes V, Schaeffer D, Mauras N, Punati J, Darmaun D: Can glutamine and growth hormone promote protein anabolism in children with cystic fibrosis? Horm Res 2002, 58(Suppl 1):21-23.

4. Bjorgell $P$, Rosberg $S$, Isaksson O, Belfrage P: The antilipolytic, insulin-like effect of growth hormone is caused by a net decrease of hormonesensitive lipase phosphorylation. Endocrinology 1984, 115(3):1151-1156.

5. Kamel A, Norgren S, Elimam A, Danielsson P, Marcus C: Effects of growth hormone treatment in obese prepubertal boys. $J$ Clin Endocrinol Metab 2000, 85(4):1412-1419.

6. Goodman HM: Effects of growth hormone on glucose utilization in diaphragm muscle in the absence of increased lipolysis. Endocrinology 1967, 81(5):1099-1103.

7. Kamel A, Norgren S, Lindgren AC, Luthman H, Arner P, Marcus C: Effect of growth hormone treatment on insulin action in adipocytes from children with Prader-Willi syndrome. Eur J Endocrinol 1998, 138(5):510-516.

8. Brooks AJ, Waters MJ: The growth hormone receptor: mechanism of activation and clinical implications. Nat Rev Endocrinol 2010, 6(9):515-525.

9. Hannon TS, Danadian K, Suprasongsin C, Arslanian SA: Growth hormone treatment in adolescent males with idiopathic short stature: changes in body composition, protein, fat, and glucose metabolism. J Clin Endocrinol Metab 2007, 92(8):3033-3039.

10. Albertsson-Wikland K, Hall K: Growth hormone treatment in short children: relationship between growth and serum insulin-like growth factor I and II levels. J Clin Endocrinol Metab 1987, 65(4):671-678.

11. Kristrom B, Carlsson B, Rosberg S, Carlsson LM, Albertsson-Wikland K. Short-term changes in serum leptin levels provide a strong metabolic marker for the growth response to growth hormone treatment in children. Swedish Study Group for Growth Hormone Treatment. J Clin Endocrinol Metab 1998, 83(8):2735-2741.

12. Ciresi A, Amato MC, Criscimanna A, Mattina A, Vetro C, Galluzzo A, D'Acquisto G, Giordano C: Metabolic parameters and adipokine profile during $\mathrm{GH}$ replacement therapy in children with $\mathrm{GH}$ deficiency. Eur J Endocrinol 2007, 156(3):353-360.

13. Aman J, Rosberg S, Albertsson-Wikland K: Effect of growth hormone treatment on insulin secretion and glucose metabolism in prepubertal boys with short stature. Eur J Endocrinol 1994, 131(3):246-250.

14. Hokken-Koelega AC, van Pareren Y, Sas T, Arends N: Final height data, body composition and glucose metabolism in growth hormone-treated short children born small for gestational age. Horm Res 2003, 60(Suppl 3):113-114.

15. Roemmich JN, Huerta MG, Sundaresan SM, Rogol AD: Alterations in body composition and fat distribution in growth hormone-deficient prepubertal children during growth hormone therapy. Metabolism 2001, 50(5):537-547.

16. Chaplin JE, Kristrom B, Jonsson B, Hagglof B, Tuvemo T, Aronson AS, Dahlgren J, Albertsson-Wikland K: Improvements in behaviour and self-esteem following growth hormone treatment in short prepubertal children. Horm Res Paediatr 2011, 75(4):291-303.

17. Carter-Su C, Schwartz J, Smit LS: Molecular mechanism of growth hormone action. Annu Rev Physiol 1996, 58:187-207.

18. Decker R, Albertsson-Wikland K, Kristrom B, Nierop AF, Gustafsson J, Bosaeus I, Fors H, Hochberg Z, Dahlgren J: Metabolic outcome of GH treatment in 
prepubertal short children with and without classical GH deficiency. Clin Endocrinol (Oxf) 2010, 73(3):346-354.

19. Wit JM, Clayton PE, Rogol AD, Savage MO, Saenger PH, Cohen P: Idiopathic short stature: definition, epidemiology, and diagnostic evaluation. Growth Horm IGF Res 2008, 18(2):89-110.

20. Albertsson-Wikland K, Rosberg S: Methods of Evaluating Spontaneous Growth Hormone Secretion. In Functional Endocrinologic Diagnostics in Children and Adolescents. Edited by Ranke M.; 1992:76-101.

21. Albertsson-Wikland K, Aronson AS, Gustafsson J, Hagenas L, Ivarsson SA, Jonsson B, Kristrom B, Marcus C, Nilsson KO, Ritzen EM, et al: Dosedependent effect of growth hormone on final height in children with short stature without growth hormone deficiency. J Clin Endocrinol Metab 2008, 93(11):4342-4350.

22. Kristrom B, Aronson AS, Dahlgren J, Gustafsson J, Halldin M, Ivarsson SA, Nilsson NO, Svensson J, Tuvemo T, Albertsson-Wikland K: Growth hormone (GH) dosing during catch-up growth guided by individual responsiveness decreases growth response variability in prepubertal children with GH deficiency or idiopathic short stature. J Clin Endocrinol Metab 2009, 94(2):483-490.

23. Albertsson-Wikland K, Kristrom B, Rosberg S, Svensson B, Nierop AF: Validated multivariate models predicting the growth response to $\mathrm{GH}$ treatment in individual short children with a broad range in $\mathrm{GH}$ secretion capacities. Pediatr Res 2000, 48(4):475-484.

24. Albertsson-Wikland K, Luo ZC, Niklasson A, Karlberg J: Swedish population-based longitudinal reference values from birth to 18 years of age for height, weight and head circumference. Acta Paediatr 2002, 91(7):739-754

25. Lofqvist C, Andersson E, Gelander L, Rosberg S, Blum WF, Albertsson Wikland K: Reference values for IGF-I throughout childhood and adolescence: a model that accounts simultaneously for the effect of gender, age, and puberty. J Clin Endocrinol Metab 2001, 86(12):5870-5876.

26. Karlberg J: On the construction of the infancy-childhood-puberty growth standard. Acta Paediatr Scand Suppl 1989, 356:26-37.

27. Devereux RB, Alonso DR, Lutas EM, Gottlieb GJ, Campo E, Sachs I, Reichek N: Echocardiographic assessment of left ventricular hypertrophy: comparison to necropsy findings. Am J Cardiol 1986, 57(6):450-458.

28. Capalbo D, Lo Vecchio A, Farina V, Spinelli L, Palladino A, Tiano C, Lettiero T, Lombardi G, Colao A, Salerno M: Subtle alterations of cardiac performance in children with growth hormone deficiency: results of a two-year prospective, case-control study. J Clin Endocrinol Metab 2009, 94(9):3347-3355

29. Nygren A, Sunnegardh J, Albertsson-Wikland K, Berggren $\mathrm{H}$, Isgaard J: Relative cardiac expression of growth hormone receptor and insulin-like growth factor-I mRNA in congenital heart disease. J Endocrinol Invest 2008, 31(3):196-200.

30. Nygren A, Sunnegardh J, Teien D, Jonzon A, Bjorkhem G, Lindell S, Albertsson-Wikland K, Kristrom B: Rapid cardiovascular effects of growth hormone treatment in short prepubertal children. Impact of treatment duration. Clin Endocrinol (Oxf) 2012, in press.

31. Schweizer R, Martin DD, Schonau E, Ranke MB: Muscle function improves during growth hormone therapy in short children born small for gestational age: results of a peripheral quantitative computed tomography study on body composition. J Clin Endocrinol Metab 2008, 93(8):2978-2983.

32. Raben MS, Hollenberg CH: Effect of growth hormone on plasma fatty acids. J Clin Invest 1959, 38(3):484-488.

33. Korpal-Szczyrska M, Balcerska A: The effect of growth hormone treatment on serum bone alkaline phosphatase in growth hormone deficient children. Pediatr Endocrinol Diabetes Metab 2008, 14(4):211-214.

34. Coelho R, Brook CG, Preece MA, Stanhope RG, Dattani MT, Hindmarsh PC: A randomised study of two doses of biosynthetic human growth hormone on final height of pubertal children with growth hormone deficiency. Horm Res 2008, 70(2):85-88.

35. Lippe BM, Kaplan SA, Golden MP, Hendricks SA, Scott ML: Carbohydrate tolerance and insulin receptor binding in children with hypopituitarism: response after acute and chronic human growth hormone administration. J Clin Endocrinol Metab 1981, 53(3):507-513.

36. Van Pareren $Y$, Mulder $P$, Houdijk $M$, Jansen $M$, Reeser $M$, Hokken-Koelega $A$ : Adult height after long-term, continuous growth hormone (GH) treatment in short children born small for gestational age: results of a randomized, double-blind, dose-response GH trial. J Clin Endocrinol Metab 2003, 88(8):3584-3590.

37. MacGorman LR, Rizza RA, Gerich JE: Physiological concentrations of growth hormone exert insulin-like and insulin antagonistic effects on both hepatic and extrahepatic tissues in man. J Clin Endocrinol Metab 1981, 53(3):556-559.

38. Moller N, Jorgensen JO, Schmitz O, Moller J, Christiansen J, Alberti KG, Orskov H: Effects of a growth hormone pulse on total and forearm substrate fluxes in humans. Am J Physiol 1990, 258(1 Pt 1):E86-E91.

39. Cohen P, Bright GM, Rogol AD, Kappelgaard AM, Rosenfeld RG: Effects of dose and gender on the growth and growth factor response to GH in GH-deficient children: implications for efficacy and safety. J Clin Endocrinol Metab 2002, 87(1):90-98.

40. Mauras N, Attie KM, Reiter EO, Saenger P, Baptista J: High dose recombinant human growth hormone $(\mathrm{GH})$ treatment of $\mathrm{GH}$-deficient patients in puberty increases near-final height: a randomized, multicenter trial. Genentech, Inc., Cooperative Study Group. J Clin Endocrinol Metab 2000, 85(10):3653-3660.

41. Wit JM, Rekers-Mombarg LT: Final height gain by GH therapy in children with idiopathic short stature is dose dependent. I Clin Endocrinol Metab 2002, 87(2):604-611.

42. Albertsson-Wikland K, Alm F, Aronsson S, Gustafsson J, Hagenas L, Hager A Ivarsson S, Kristrom B, Marcus C, Moell C, et al: Effect of growth hormone (GH) during puberty in GH-deficient children: preliminary results from an ongoing randomized trial with different dose regimens. Acta Paediatr Suppl 1999, 88(428):80-84.

43. Wit JM, Rekers-Mombarg LT, Cutler GB, Crowe B, Beck TJ, Roberts K, Gill A, Chaussain JL, Frisch $\mathrm{H}$, Yturriaga R, et al: Growth hormone (GH) treatment to final height in children with idiopathic short stature: evidence for a dose effect. J Pediatr 2005, 146(1):45-53.

doi:10.1186/1472-6823-12-26

Cite this article as: Decker et al: Different thresholds of tissue-specific dose-responses to growth hormone in short prepubertal children. $B M C$ Endocrine Disorders 2012 12:26.

\section{Submit your next manuscript to BioMed Central and take full advantage of:}

- Convenient online submission

- Thorough peer review

- No space constraints or color figure charges

- Immediate publication on acceptance

- Inclusion in PubMed, CAS, Scopus and Google Scholar

- Research which is freely available for redistribution 